\title{
Nutrition Practice and Knowledge of First-Year Medical Students
}

\author{
Robyn Perlstein, ${ }^{1}$ Scott McCoombe, ${ }^{2}$ Susie Macfarlane, ${ }^{3}$ \\ Andrew Colin Bell, ${ }^{2}$ and Caryl Nowson ${ }^{1}$ \\ ${ }^{1}$ Institute of Physical Activity and Nutrition (IPAN), School of Exercise and Nutrition Sciences, Deakin University, \\ Geelong, VIC, Australia \\ ${ }^{2}$ School of Medicine, Deakin University, Geelong, VIC, Australia \\ ${ }^{3}$ School of Exercise and Nutrition Sciences, Deakin University, Geelong, VIC, Australia
}

Correspondence should be addressed to Robyn Perlstein; robyn.perlstein@deakin.edu.au

Received 31 March 2017; Accepted 6 July 2017; Published 27 August 2017

Academic Editor: Terrence M. Shaneyfelt

Copyright (C) 2017 Robyn Perlstein et al. This is an open access article distributed under the Creative Commons Attribution License, which permits unrestricted use, distribution, and reproduction in any medium, provided the original work is properly cited.

Objectives. To compare the knowledge of Australian dietary recommendations to the dietary practices of first-year medical students. Design. Over a period of four years, anonymous online surveys were completed by medical students attending a first-year nutrition lecture. Background. There is little information on the nutritional knowledge and dietary practices of medical students. Setting. First-year postgraduate university medical students, Geelong, Victoria, Australia. Participants. Between the years 2012 and 2016 , $32 \%-61 \%$ of first-year students completed the survey. Phenomenon of Interest. Student's knowledge of dietary guidelines and related practices. Analysis. The frequency of response was assessed across the different year cohorts using descriptive statistics. Results. Between 59\% and 93\% of first-year students correctly identified the recommended daily servings for fruit, and between $61 \%$ and $84 \%$ knew the vegetable recommendations. In contrast only $40 \%-46 \%$ met the guidelines for fruit and $12 \%-19 \%$ met the guidelines for vegetables. Conclusions and Implications. Discrepancies between students' nutrition knowledge and behavior can provide learning opportunities. With low rates of fruit and vegetable consumption in medical students, increased awareness of links between nutrition and health, together with encouragement to make behavioral changes, may increase the skills of graduates to support patients in improving dietary intake.

\section{Introduction}

Nutrition plays a vital role in the prevention and treatment of acute and chronic disease [1] and the Australian Medical Council [2] considers that medical graduates should be able to manage chronic disease, of which nutrition is a major risk factor. Although some nutrition care is provided in general practice [3], it does not match the growth in the burden of nutrition related chronic disease in Australia and elsewhere [4]. Medical practitioners are not able to address nutrition adequately because training in nutrition in medical schools is very poor $[5,6]$. Reasons for the minimal nutrition content include an already crowded curriculum, lack of adequately trained teaching staff, and a scarcity of advocates for nutrition education in teaching schools $[7,8]$.

Medical students appear to be dissatisfied with current levels of nutrition education. In a recent study [9] in a cohort of over 1000 Australian medical students, less than half felt that they could competently discuss nutrition with patients, even though they felt nutrition was essential in their education and healthcare practices. A survey in the USA of over 2300 medical students from 16 universities suggested that nutrition education alone did not provide the skills needed in counselling patients on nutrition related issues [10].

Adult learning theories guide healthcare educators in appropriate teaching styles to maximise learning [11]. Each style has its own strengths and all overlap, but those relevant in medical education include experiential learning [12], Transformative Learning Theory [13], Reflective Models [14], and Social Constructionism [15]. Knowledge is an important foundation for preparing graduates for the workforce [16], but surface learning [17] should only be a small part of medical education with more appropriate experiential learning opportunities integrated into the curriculum. 
TABLE 1: Gender and educational backgrounds of first-year postgraduate students (2013-16) (percent).

\begin{tabular}{lccccc}
\hline Year & Total $n$ & Male/female $\%$ & Science $\%$ & Allied health $\%$ & Arts/commerce/engineering $\%$ \\
\hline 2013 & 136 & $45 / 55$ & 66 & 24 & 10 \\
2014 & 134 & $38 / 62$ & 64 & 26 & 10 \\
$2015^{*}$ & 138 & $51 / 49$ & 62 & 23 & 7 \\
2016 & 147 & $45 / 55$ & 79 & 17 & 4 \\
\hline
\end{tabular}

${ }^{*}$ Complete details not available on all students' previous education.

Therefore the aim of this study was to determine the nutrition practices and knowledge of nutritional recommendations for health of first-year students enrolled in a graduate entry medical course at an Australian university. We also aimed to assess the level of discordance between self-reported nutritional practices and knowledge which would inform the development of effective experiential learning opportunities that connect on a personal level to student experiences.

\section{Methods}

2.1. Study Sample and Survey Administration. Deakin University has approximately 130-150 medical students enrolled in the postgraduate four-year Bachelor of Medicine, Bachelor of Surgery (MBBS) course each year. Students attending the lectures were asked to voluntary participate in the anonymous survey. First-year Deakin University medical students (see Table 1 for participant demographics) completed 10 survey questions during two fifty-minute nutrition focused public health medicine lectures delivered in the second semester of their course. These surveys were conducted once each year over four years (2013-2016). The lectures were entitled the "Role of Nutrition in Health at a Population Level" and "Role of Nutrition in Cardiovascular Disease." These lectures generally ran sequentially over a two hour allocated class time. Responses to survey questions were recorded through an anonymous classroom response system (Turning Point: LUL Technology Pty. Limited; Turning Point 5 Interactive PowerPoint ${ }^{\circledR}$ software; and Socrative Student Response by Mastery Connect ${ }^{\circledR}$ Version 2.2.2). These provided instant information to students on the distribution of responses. Also, details of the academic backgrounds of these students and the numbers enrolled over the four years were obtained from the Deakin Medical School, with data regarding student's previous degree in all years except 2015, where this data was not documented in $8 \%$ of students.

2.2. Survey Design and Content. The survey consisted of ten multiple choice questions (Table 2). Five questions were administered in each of the lectures: two on student's lifestyle practices, such as the number of serves per day of certain foods consumed; three on participant knowledge of recommendations such as current national government recommendations relating to these foods [18]. The questions on participants' lifestyle practices were administered prior to the knowledge questions and prior to them receiving nutrition lecture content that related to these questions.
The five questions in the first lecture were devised by the authors and related to fruit and vegetable intake and knowledge of the Australian Dietary Guidelines. Participants were asked to select the option that represented their average daily fruit and vegetable intake ranging from less than 1 serve to 5 or more serves. Responses to these questions were categorised according to whether the number of serves met the recommended number of serves, that is, met the daily guidelines of 2 serves of fruit or 5 serves of vegetables, or did not meet the guidelines. The next questions asked participants to identify the recommended number of servings of daily fruit and vegetables (options ranged from 1 to 5 serves per day).

The last question tested participants' knowledge of the impact of consuming adequate amounts of fruits and vegetables on the likelihood of developing a variety of chronic diseases. In 2013 this included options such as reducing the risk of disease including cardiovascular disease, vitamin insufficiency, cancer, and fractures; in 2014 options included reducing the risk of iodine deficiency, vitamin insufficiency, retinopathy, or reducing the risk of all three; and in 2015 and 2016 included reducing the risk of stroke and inflammatory bowel disease. The options were changed to indicate an understanding of the impact of fruit and vegetable intake on the risk of developing disease, by reflecting on results obtained each year in comparison to the previous year.

The five questions in the second lecture are related to the participants' own dietary intake of fat and salt as well as current dietary recommendations for salt. The first question asked participants to select one food that contained significant amounts of saturated or trans fatty acids from a list of 7 commonly eaten foods including (in 2013 and 2014) cheddar cheese, roast chicken, biscuits, chips in canola oil, cottage cheese, skim milk, and battered fish. In 2015 and 2016 the question asked students to select the food which did not have significant amounts of saturated fatty acids, with similar options provided but allowing only one correct response.

Students were asked to select the correct recommended daily salt intake. In 2013 and 2014 there were 3 possible responses and in 2015 and 2016 these were increased to 7 possible responses. The three possible responses were provided as ranges of intake but to reduce confusion, individual amounts were provided as choices. Responses were classified as correct or incorrect.

The subsequent questions asked participants about their use of salt at home, such as adding salt in cooking and adding salt at the table, with responses ranging from never, rarely, sometimes, or often. Practices related to the use of salt in cooking and at the table were assessed and categorised as 


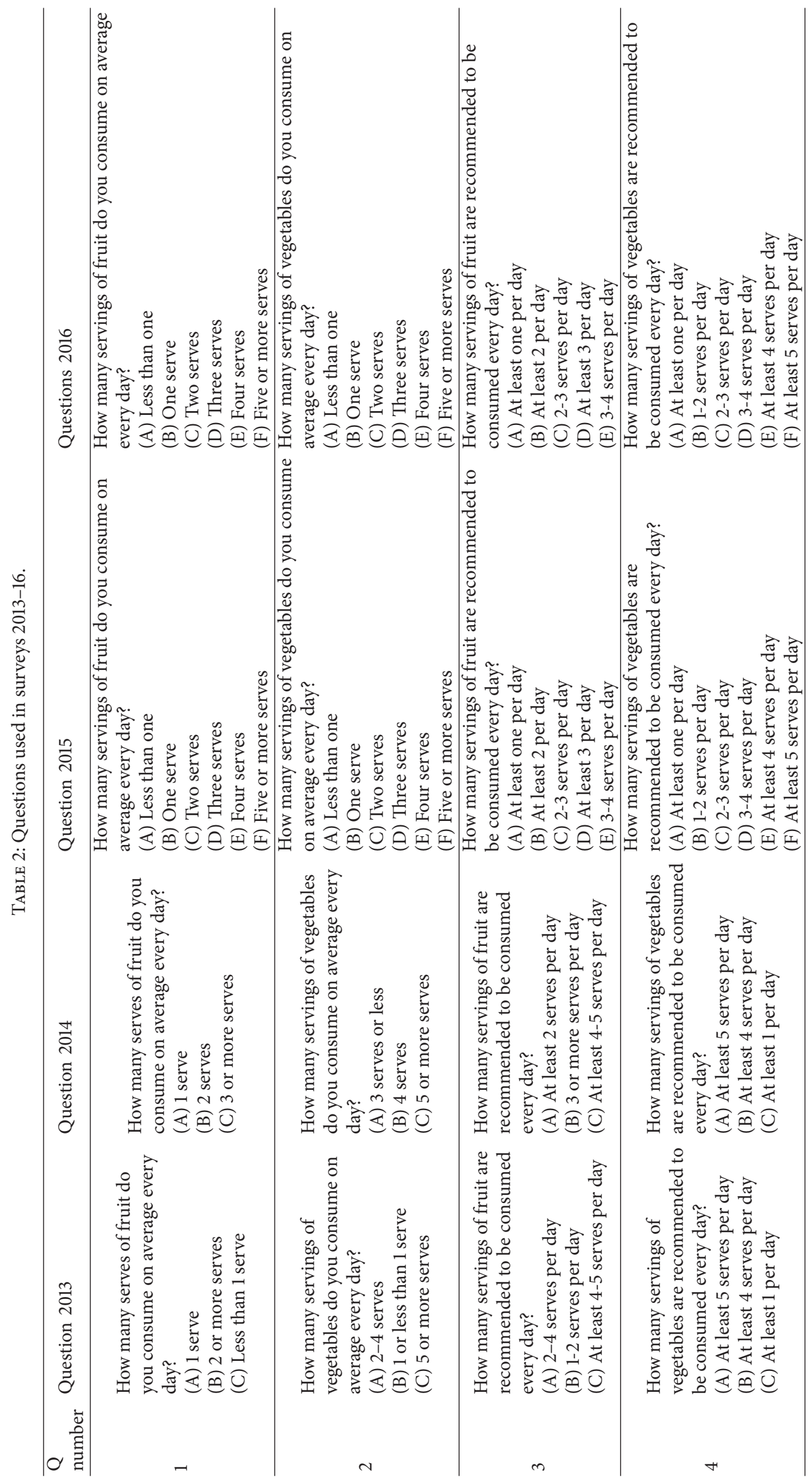




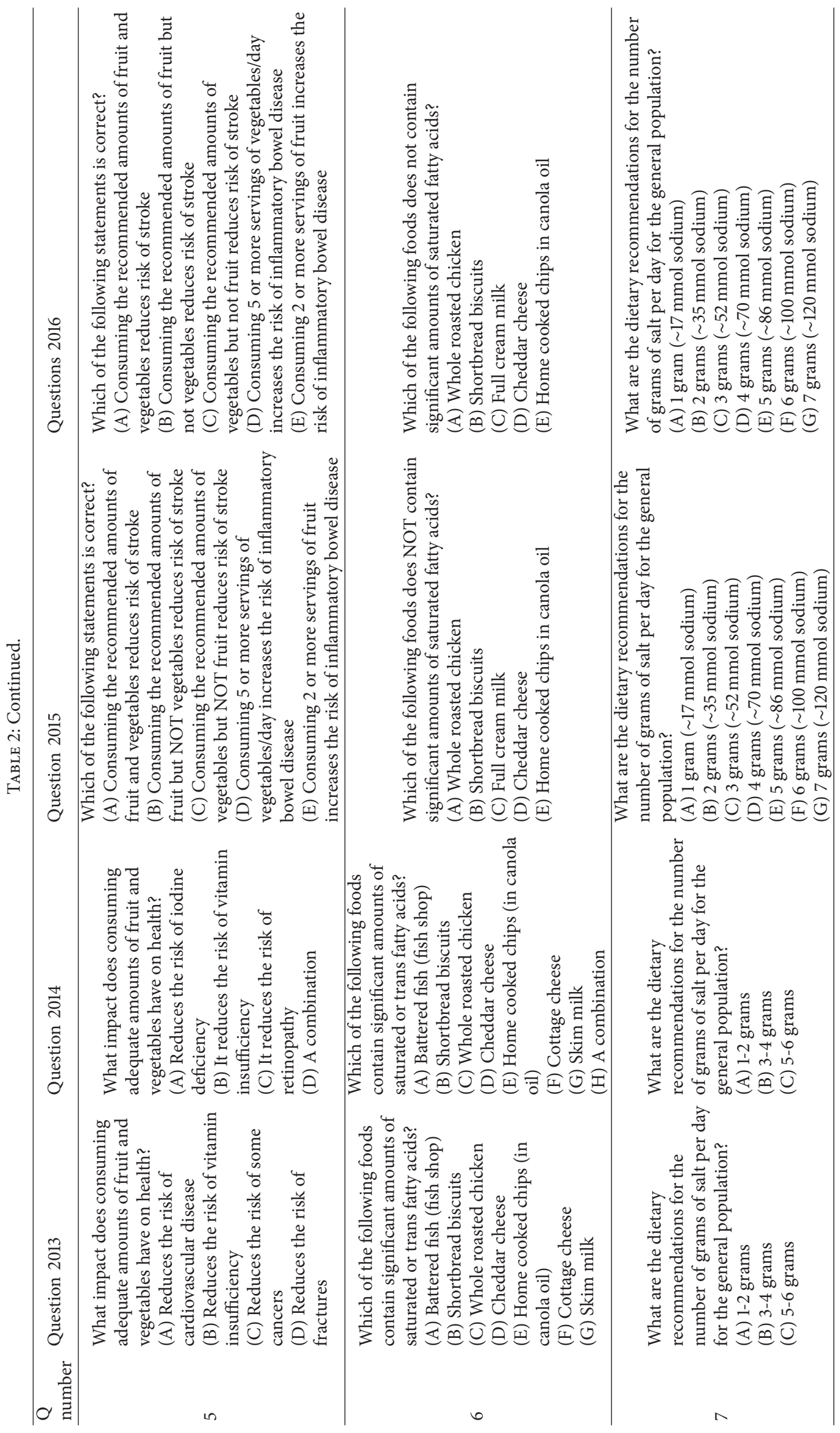




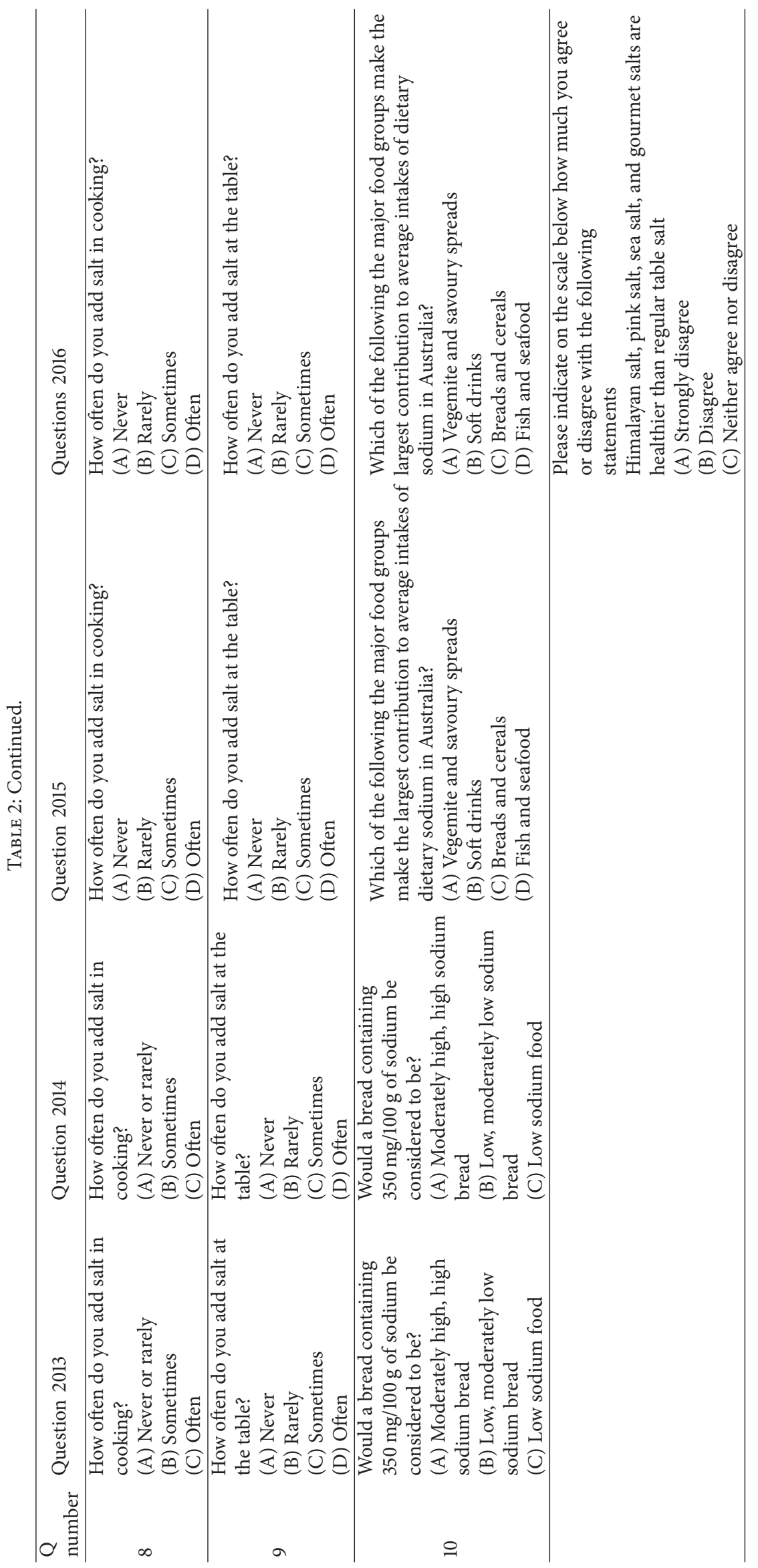


TABLE 3: Correct/desirable student responses (percent) nutrition practice and knowledge: fruit, vegetables, and salt (2013-16).

\begin{tabular}{|c|c|c|c|c|c|}
\hline Responses to multichoice questions (questions $1,2,3,4,7,8$, and 9) \% & 2013 & 2014 & 2015 & 2016 & $\begin{array}{c}\text { Median } \\
(2013-16)\end{array}$ \\
\hline Knew the guidelines for fruit* & 93 & 68 & 59 & 41 & 61 \\
\hline Meeting guidelines for daily fruit ( $\geq 2$ serves) & 44 & 45 & 40 & 46 & 44 \\
\hline Knew the guidelines for vegetables & 66 & 61 & 75 & 84 & 71 \\
\hline Meeting guidelines for daily vegetables ( $\geq 5$ serves) & 12 & 19 & 16 & 16 & 16 \\
\hline Knew the guidelines for daily salt intake** & 20 & 26 & 8 & 13 & 17 \\
\hline Salt in cooking (never/rarely) & 47 & 34 & 47 & 41 & 44 \\
\hline Salt at the table (never/rarely) & 76 & 73 & 75 & $85^{* *}$ & 76 \\
\hline Consuming 1 serve fruit or less & 56 & 8 & 28 & 29 & 19 \\
\hline Consuming $\leq 1$ serve vegetables & 19 & 7 & 7 & 13 & 10 \\
\hline
\end{tabular}

${ }^{*}$ The question was rewritten after 2013 to incorporate more suitable responses. ${ }^{* *}$ There were 3 possible responses in $2013 / 14$ versus 7 in $2015 / 16$.

TABLE 4: Nutrition knowledge: health impacts of consuming fruit and vegetables, saturated fat levels in foods, and foods containing sodium (percent).

\begin{tabular}{|c|c|c|c|c|c|}
\hline$\%$ correct responses & 2013 & 2014 & 2015 & 2016 & Median \\
\hline Which chronic conditions do fruit and vegetables have an impact on?* & 64 & 87 & 71 & 72 & 71 \\
\hline Which of the foods listed contain high or low levels of saturated fat/transfat?* & 88 & 70 & 52 & 30 & 61 \\
\hline Which of the foods listed contributing high/low levels of sodium?* & 76 & 74 & 70 & 58 & 72 \\
\hline
\end{tabular}

${ }^{*}$ Specific components of questions changed each year.

meeting guidelines if respondents never or rarely added salt at the table/in cooking.

In 2013 and 2014 the final question asked students to classify bread with $350 \mathrm{mg}$ sodium as a moderately high to high sodium food, low-moderately low sodium food, or a low sodium food. In 2015 and 2016 this question was modified to ask which food groups in the Australian diet contribute the highest average sodium levels, with options including savory spreads, soft drinks, breads, cereals, fish, and seafood. This was so the students considered a wider range of foods than just bread as being high sources of sodium.

2.3. Ethical Considerations. Ethical approval was received from the Deakin University Human Ethics Advisory Group (HEAG-H 80_2015). The students indicated their consent in the survey by completing it.

2.4. Data Analysis. The frequency of response was assessed across the different year cohorts using descriptive statistics.

\section{Results}

The variability in the results across the three years indicate no obvious or distinct trends in knowledge and dietary practices of these first-year medical students. Approximately two-thirds (e.g., 66\% in 2013) of students across all four cohorts entered the course with an undergraduate degree in science although this proportion was greater (79\%) in 2016. One-quarter of the students across the four years surveyed were from allied health backgrounds, although this was lower in 2016 at 17\%. Other fields of study were arts, engineering, and commerce, these making a combined total $4 \%-10 \%$ of students from 2012 to 2016.

The number of students who attended the nutrition lecture and therefore undertook the survey ranged from $32 \%$ to $61 \%$ of the enrolled student cohort. Most students attending the lecture completed all the survey questions posed during the session (range 60\%-100\%).

3.1. Knowledge. Over the four first-year cohorts, the proportion of participants who knew the recommended guidelines for fruit intake ranged between $59 \%$ and $93 \%$ (Table 3). The higher number of correct responses in 2013 (93\%) may have been due to the question being modified in later surveys so as to be more discriminating. The proportion of participants who knew the guidelines for vegetable intake ranged from $61 \%$ to $84 \%$ (Table 3 ) with the largest proportion of correct responses (84\%) seen in the 2016 cohort. Most participants were aware of the positive health impacts of consuming adequate amounts of fruits and vegetables (64\%-87\%) (Table 4).

Few participants correctly identified the population guidelines for sodium (8\%-26\%) (Table 3) although more than half were aware of the major food types that contributed to dietary sodium intake (58\%-76\%) (Table 4). The proportion of participants who knew the foods containing significant amounts of saturated fats varied over the cohorts, ranging from $30 \%$ to $88 \%$ (Table 4 ), but this question was updated each year.

3.2. Practice. Less than half of participants (40\%-46\%) reported meeting the guidelines for fruit. Even fewer students met the guidelines for vegetables (12\%-19\%) (Table 3). 
Overall the results indicate that most participants knew the dietary recommendations for fruit and vegetables (Table 3). However a much smaller proportion of participants met the recommended guidelines for fruit $(61 \%$ of participants knew the guidelines versus $44 \%$ of participants reported consuming at least two serves/day). There was an even greater discordance for vegetable knowledge and intake: $71 \%$ of students knew the guidelines but only $16 \%$ of participants reported consuming at least five serves/day.

Most participants reported not using salt at the table (73\%-85\%), whereas on average just under half reported using salt in cooking $(34 \%-47 \%)$ (Table 3), although few participants knew the suggested guidelines for daily intake of salt (17\%).

\section{Discussion}

This study aimed to assess the knowledge of dietary recommendations and dietary practices of first-year medical students and to assess differences in self-reported nutrition practices and knowledge. We found that over half of the participants knew the recommended number of serves of fruits and vegetables per day, while less than half of the students met the recommended number of serves of fruit per day and less than one-fifth reported consuming the recommended number of serves of vegetables per day. Few students were aware of the recommended daily salt intake but were aware that salt intake should be reduced. Most used no salt at the table while just over half of the students added salt in cooking.

We found that, on average, over half of the first-year medical students participating in our study knew the recommended number of serves of fruits and vegetables. Similarly we found that most participants were aware of the health risks associated with consuming insufficient fruit and vegetables as students receive lecture material during their first-year outlining the health benefits of consuming adequate amounts in the context of the physiological mechanisms of cardiovascular disease.

The higher proportion of participants with knowledge of the dietary recommendations (compared with less than half of the general population [19]) may also be related to their educational background as about 1/4 were graduates from allied health backgrounds and more than half had a science degree (which included biological sciences) in which dietary recommendations for health may have been included in the curriculum. It has been assumed that medical students' knowledge of healthy eating would be higher than the general student population. One study conducted in Pakistan compared the knowledge of healthy diet and lifestyle habits of medical versus nonmedical students and found that $35 \%$ of medical students knew the dietary and lifestyle recommendations, while only $14 \%$ of nonmedical students knew the guidelines [20]. In contrast a study at a large Canadian University Campus found that only one-quarter of students from any discipline including health knew the recommended number of serves of fruit and vegetables [21], which indicates a much lower level of knowledge than our postgraduate study cohorts.
The Australian Dietary Guidelines [18] state "Limit intake of foods and drinks containing added salt...; do not add salt to foods in cooking or at the table." Other government agencies such as the World Health Organisation recommend an upper limit of $2000 \mathrm{mg}$ sodium (5 g salt) for adults [22]. Few students at the University participating in this current study were aware of the recommended daily salt intake, but as there are a number of different recommended maximum targets for daily salt intakes from different public health agencies [23], this outcome was not surprising.

Although most students knew the Australian dietary recommendations for fruit and vegetables, less than half of the students met the recommended number of serves of fruit/day and less than one-fifth reported consuming the recommended number of serves of vegetables. It may be assumed that medical students' knowledge of healthy eating would be higher and therefore their lifestyle practices better than the general population, but in a study conducted in Polish first-year health and medical students, only $29 \%$ of the students reported eating any fruit or vegetables daily [24]. However there was no comparison of their intake to that of the general Polish population. A study conducted in Pakistan found that the dietary habits of medical students were not significantly different to that of nonmedical students, although a greater proportion of medical students knew the dietary guidelines [20].

Of participating first-year postgraduate medical students in this study, only $12-16 \%$ reported meeting the recommended 5 serves of vegetables day. This is not markedly different compared to the general Australian population where only $10 \%$ of participants report meeting this target [25]. In sixteen US medical schools only $11.4 \%$ of students surveyed met the national guidelines for fruit and vegetable intake and consumption decreased further in the latter years of medical school [10]. In contrast a study conducted in Canada found $64 \%$ of health science students reported meeting guidelines for fruit and vegetable intake compared with $48 \%$ of those in other disciplines (arts, law, and business) [21].

Although most participants were not aware of the specific target intakes for salt in Australia, it appears that most were aware of the recommendations to reduce salt intake. $76 \%$ never or rarely used salt at the table (compared to half of the Australian adult population), while $44 \%$ of students never or rarely added salt in cooking, similar to the general population [25] who are aware of the link between salt intake and disease (Personal communication Dr. Carley Grimes 14/12/2016).

Discordance between knowledge of and actual dietary behaviors in medical students has been established in other countries. Sajwani et al. [20] found that higher knowledge levels in Pakistani medical students were not reflected in their dietary practices. A study in Angola reported that although medical students were aware of the health consequences of a high salt intake, few looked at sodium levels on food labels before consuming products [26]. Another survey indicated that UK healthcare students were well informed about health related consequences of a high salt intake but had not reduced their own consumption of salt [27].

We have found that this gap/discrepancy between nutrition knowledge and nutrition behavior provides a relevant 
learning opportunity for students and facilitates discussion and dialogue relating to the difficulties they and their future patients are very likely to face in following dietary guidelines. This is particularly true given the active strategies required to achieve a daily intake of 5 serves of vegetables/day. Given the low rates of fruit and vegetable consumption in this population group who may be expected to have greater knowledge and appreciate the importance in adhering to dietary recommendations, the discussion of barriers and enhancers is a useful teaching opportunity.

Experiential Learning encourages reflection and autonomy in thinking and suggests that learners can change their frame of reference if underlying assumptions are challenged [28]. For example if students see that their vegetable intake is lower than recommended then self-reflection may encourage a change in behavior. This may lead graduates to support future clients to institute behavior change. This type of adult learning is being used with pharmacy students [29] and nursing students [30] and in medical education [31] to encourage students to reflect on their own actions or assumptions [32]. Methods that have been successfully implemented include pharmacy students observing other allied health students in patient simulations [33], explorations of medical students reactions and perceptions after seeing photographs of patients from lower socioeconomic groups [34], and nursing students who spent time with mental health patients in the classroom rather than in a clinical setting [30]. Progression from a student to a health professional relies on experiential learning and participation.

Experiential learning, utilising the link between new knowledge and previous experiences (such as dietary behaviors), has the potential to enable learning with a longterm impact. As Yardley et al. [28] explained, experience is the focus of lifelong learning, and knowledge is created through the transformation of experience. There are a range of experiential learning opportunities related to nutrition included in the medical curriculum, such as team based learning activities focussing on interpreting food labels and peer dietary recall. Vargas reported in 2014 that in secondyear US medical students, nutrition activities involving selfassessment of dietary habits led to improvements in heart healthy eating habits [35]. Interactive nutrition cooking programs in medical education have also been successfully integrated into the curriculum in some US medical courses resulting in increased fruit and vegetable intake and improved competency in counselling patients on nutrition [36]. Health care providers who undertook a program that included selfreflection on their own dietary behaviors led to improved personal practices and a higher rate of patient counselling [37]. However contrasting findings of a study of medical students who undertook a 12 -week nutrition course resulted in increased awareness of their own dietary choices but not a large improvement in dietary practices [38].

A number of medical schools encourage students to provide preventive counselling, but medical graduates may be more prepared if as students they are physically active and eat well. Physicians in the US who did not smoke, were of a healthy weight, exercised regularly, and drank little alcohol were more likely to counsel clients in these areas. They also counselled a wider range of patients and were more forceful in giving advice [39]. One US study found that medical students who consumed more fruit and vegetables and ate a healthy diet were more likely to rate nutrition counselling highly relevant in medical practice [10]. Therefore medical students who develop healthy dietary practices are likely to have a greater capacity to address nutrition and lifestyle issues with their patients.

Limitations of this study include the inclusion of participants from only one university and self-reporting of dietary practices [40]. Wording of some of the questions were revised over the 4 years to make the questions more challenging which is likely to have impacted on responses in the different classifications over the 4 years. Additionally not all students attended the nutrition lectures and therefore responses included may not be representative of all the firstyear medical student population.

\section{Implications for Research and Practice}

Most participants knew the dietary recommendations for fruit and vegetables, yet less than half achieved the recommended number of daily servings for fruit and even fewer for vegetables. While very few knew the guidelines for the daily intake of salt, most students followed the recommendation to avoid adding salt to food at the table.

As medical students' attitudes to dietary recommendations are influenced by personal eating habits, students consuming a diet consistent with the dietary guidelines are more likely to recommend the same for their patients. It would be of interest in future research to evaluate whether learning activities that encourage the development of healthy lifestyle changes in medical students ultimately translate to supporting patients in making behavioral lifestyle changes to improve health.

Learning activities that help students identify and reflect on their nutrition practices and knowledge can be implemented to stimulate personal reflection and discussion by students. This has the potential to have a long-term impact on knowledge and lifestyle behavioral practices, setting the scene for medical graduates to be better able to support their patients in making and maintaining positive lifestyle behaviors. Accordingly improved patient health outcomes are likely to be achieved if doctors self-reflect on their own lifestyle behaviors and discuss barriers and promoters of healthy dietary practices in their training. Future research is needed to explore whether medical students in higher year levels maintain similar knowledge levels and behaviors. Embedding experiential learning opportunities related to lifestyle practices within the medical curriculum has the potential to facilitate an improvement in students' dietary practices, which may ultimately assist them in supporting healthy lifestyles of their patients.

\section{Conflicts of Interest}

The authors declare that they have no conflicts of interest. 


\section{Acknowledgments}

Thanks are due to all of the students who participated in these surveys and the Deakin Medical School staff for assisting.

\section{References}

[1] World Health Organisation, Global health risks: mortality and burden of disease attributable to selected major risks, 2009.

[2] Australian Medical Council, Standards for Assessment and Accreditation of Primary Medical Programs by the Australian Medical Council, 2012.

[3] L. Ball, M. Leveritt, S. Cass, and W. Chaboyer, "Effect of nutrition care provided by primary health professionals on adults' dietary behaviours: a systematic review," Family Practice, vol. 32, no. 6, pp. 605-617, 2015.

[4] World Health Organisation, "Diet, nutrition and the prevention of chronic diseases," World Health Organ Tech Rep Ser 916, 2003.

[5] L. Ball, J. Crowley, C. Laur, M. Rajput-Ray, S. Gillam, and S. Ray, "Nutrition in medical education: reflections from an initiative at the University of Cambridge," Journal of Multidisciplinary Healthcare, vol. 7, pp. 209-215, 2014.

[6] K. M. Adams, M. Kohlmeier, and S. H. Zeisel, "Nutrition education in U.S. medical schools: latest update of a national survey," Academic Medicine, vol. 85, no. 9, pp. 1537-1542, 2010.

[7] R. A. Dimaria-Ghalili, M. Edwards, G. Friedman et al., "Capacity building in nutrition science: revisiting the curricula for medical professionals," Annals of the New York Academy of Sciences, vol. 1306, no. 1, pp. 21-40, 2013.

[8] R. L. Weinsier, J. R. Boker, E. B. Feldman, M. S. Read, and C. M. Brooks, "Nutrition knowledge of senior medical students: a collaborative study of southeastern medical schools," American Journal of Clinical Nutrition, vol. 43, no. 6, pp. 959-968, 1986.

[9] N. Schoendorfer and J. Schafer, "Enabling valuation of nutrition integration into MBBS program," Journal of Biomedical Education, vol. 2015, pp. 1-6, 2015.

[10] E. H. Spencer, E. Frank, L. K. Elon, V. S. Hertzberg, M. K. Serdula, and D. A. Galuska, "Predictors of nutrition counseling behaviors and attitudes in US medical students," The American Journal of Clinical Nutrition, vol. 84, no. 3, pp. 655-662, 2006.

[11] J. Bransford, How people learn. Brain, mind experience and school, National Academies Press, Washington, D.C., USA, 2000.

[12] D. Kolb, Experiental Learning; Experience as The Source of Learning And Development, Prentice-Hall, New Jersey, NJ, USA, 1984.

[13] Mezirow, Transformative Learning: Theory to practice . In Defence of the Lifeworld, Suny Press, New York, NY, USA, 1975.

[14] D. A. Schon, The Reflective Practitioner, Jossey-Bass, San Fransisco, CA, USA, 1983.

[15] V. Burr, Social Constructionism, Taylor \& Francis, New York, NY, USA, 2nd edition, 2003.

[16] G. E. Miller, "The assessment of clinical skills/competence/ performance," Academic Medicine, vol. 65, supplement, pp. S63S67, 1990

[17] D. C. M. Taylor and H. Hamdy, "Adult learning theories: implications for learning and teaching in medical education: AMEE Guide No. 83," Medical Teacher, vol. 35, no. 11, pp. e1561e1572, 2013.
[18] Australian Government National Health and Medical Research Council, Australian Guide to Healthy Eating, 2015.

[19] A. Worsley, "Food Knowledge Survey 2011: Preliminary Report," Deakin University, Centre for Physical Activity and Nutrition Research, 2011.

[20] R. A. Sajwani, S. Shoukat, and R. Raza, "Knowledge and practice of healthy lifestyle and dietary habits in medical and nonmedical students of Karachi, Pakistan," Journal of the Pakistan Medical Association, vol. 59, no. 9, pp. 650-655, 2009.

[21] J. I. Matthews, L. Doerr, and P. D. N. Dworatzek, "University students intend to eat better but lack coping self-efficacy and knowledge of dietary recommendations," Journal of Nutrition Education and Behavior, vol. 48, no. 1, pp. 12-19.el, 2016.

[22] World Health Organisation, Sodium Intake for Adults and Children, 2012.

[23] National Heart Foundation Australia, Salt and Hypertension (Professional Paper), 2007, National Heart Foundation Australia. Salt and Hypertension (Professional Paper.

[24] W. Likus, D. Milka, G. Bajor, M. Jachacz-Łopata, and B. Dorzak, "Dietary habits and physical activity in students from the medical university of silesia in poland," Roczniki Państwowego Zakładu Higieny, vol. 64, no. 4, pp. 317-324, 2013.

[25] Australian Bureau of Statistics, "National Nutrition Survey," 2014, http://www.abs.gov.au/australianhealthsurvey.

[26] P. Magalhaes, E. J. R. Sanhangala, I. M. Dombele, H. S. N. Ulundo, D. P. Capingana, and A. B. T. Silva, "Knowledge, attitude and behaviour regarding dietary salt intake among medical students in Angola," Cardiovascular Journal of Africa, vol. 26, no. 2, pp. 57-62, 2015.

[27] R. Kabir, A. Ozkaya, and S. Ozkaya, "Assessment of salt intake behaviour among undergraduate health care students studying in London," International Journal of Community Medicine and Public Health, pp. 2734-2739, 2016.

[28] S. Yardley, P. W. Teunissen, and T. Dornan, "Experiential learning: transforming theory into practice," Medical Teacher, vol. 34, no. 2, pp. 161-164, 2012.

[29] J. M. Lonie and K. R. Desai, "Using transformative learning theory to develop metacognitive and self-reflective skills in pharmacy students: a primer for pharmacy educators," Currents in Pharmacy Teaching and Learning, vol. 7, no. 5, pp. 669-675, 2015.

[30] B. Rush, "Mental health service user involvement in nurse education: a catalyst for transformative learning," Journal of Mental Health, vol. 17, no. 5, pp. 531-542, 2008.

[31] C. M. Wittich, D. A. Reed, F. S. McDonald, P. Varkey, and T. J. Beckman, "Perspective: transformative learning: a framework using critical reflection to link the improvement competencies in graduate medical education," Academic Medicine, vol. 85, no. 11, pp. 1790-1793, 2010.

[32] A. M. Brockbank, Facilitating Reflective Learning In Higher Education, McGraw-Hill Education, 2007.

[33] P. Paul, J. K. Olson, C. Sadowski et al., "Interprofessional simulation learning with nursing and pharmacy students: a qualitative study," Quality Advancement in Nursing Education, vol. 1, article 6, 2014.

[34] C. Loignon, A. Boudreault-Fournier, K. Truchon, Y. Labrousse, and B. Fortin, "Medical residents reflect on their prejudices toward poverty: a photovoice training project," BMC Medical Education, vol. 14, no. 1, article 274, 2014. 
[35] E. J. Vargas and R. Zelis, "Integrating nutrition education into the cardiovascular curriculum changes eating habits of secondyear medical students," Journal of Clinical Lipidology, vol. 8, no. 2, pp. 199-205, 2014.

[36] D. J. Monlezun, B. Leong, E. Joo, A. G. Birkhead, L. Sarris, and T. S. Harlan, "Novel longitudinal and propensity score matched analysis of hands-on cooking and nutrition education versus traditional clinical education among 627 medical students," Advances in Preventive Medicine, vol. 2015, pp. 1-8, 2015.

[37] I. Shai, D. Erlich, A. D. Cohen et al., "The effect of personal lifestyle intervention among health care providers on their patients and clinics; the promoting health by self experience (PHASE) randomized controlled intervention trial," Preventive Medicine, vol. 55, no. 4, pp. 285-291, 2012.

[38] J. Crowley, L. Ball, M. D. Leveritt, B. Arroll, D. Y. Han, and C. Wall, "Impact of an undergraduate course on medical students' self-perceived nutrition intake and self-efficacy to improve their health behaviours and counselling practices," Journal of Primary Health Care, vol. 6, no. 2, pp. 101-107, 2014.

[39] K. B. Wells, C. E. Lewis, B. Leake, and J. E. Ware Jr., "Do physicians preach what they practice? A study of physicians' health habits and counseling practices," The Journal of the American Medical Association, vol. 252, no. 20, pp. 2846-2848, 1984.

[40] N. V. Dhurandhar, D. Schoeller, A. W. Brown et al., "Energy balance measurement: when something is not better than nothing," International Journal of Obesity, vol. 39, pp. 1109-1113, 2015. 


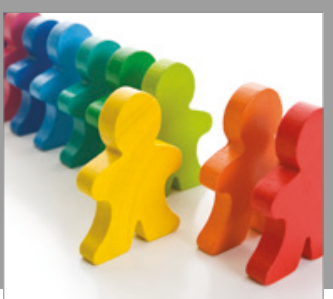

Autism

Research and Treatment
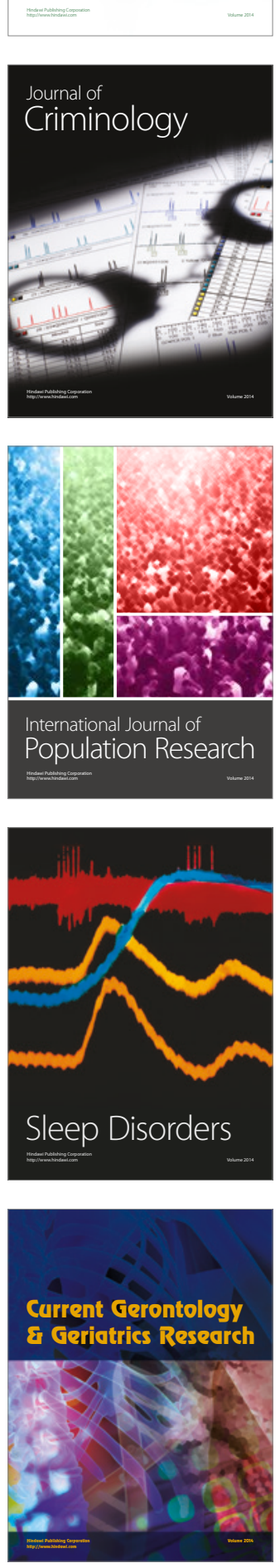

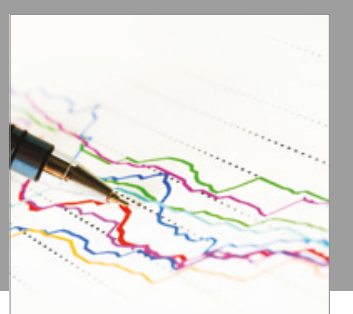

Economics

Research International

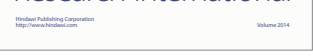

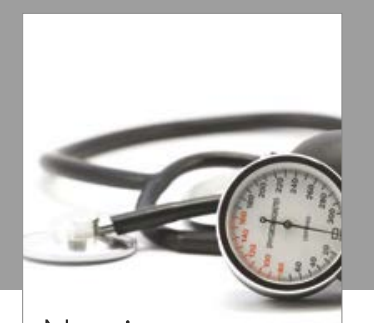

Nursing

Research and Practice

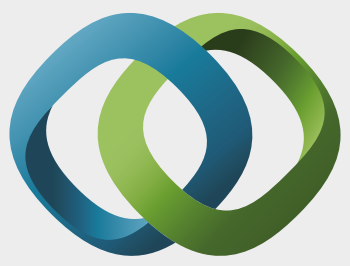

\section{Hindawi}

Submit your manuscripts at

https://www.hindawi.com
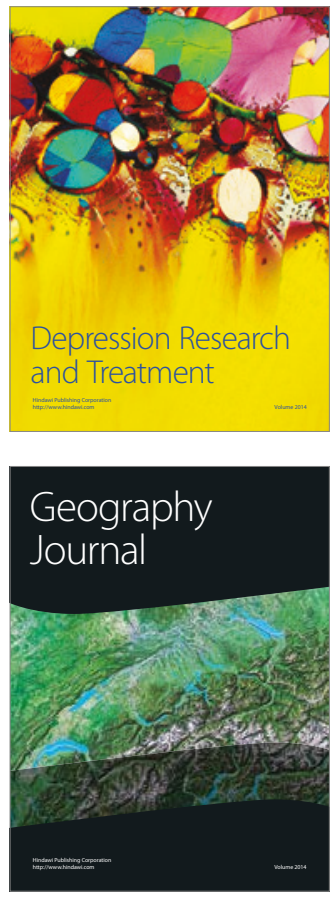
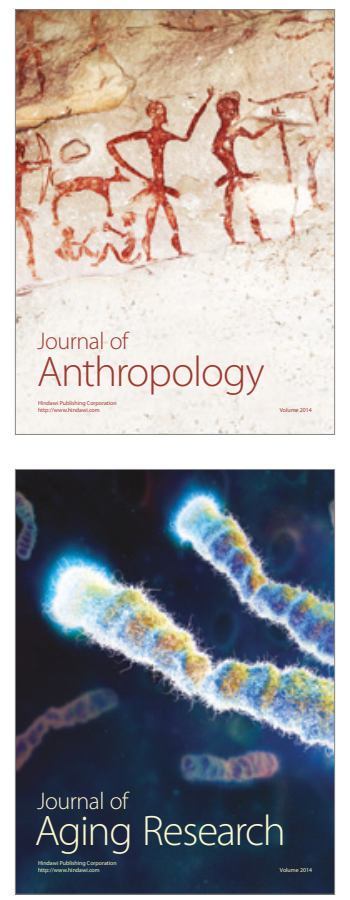
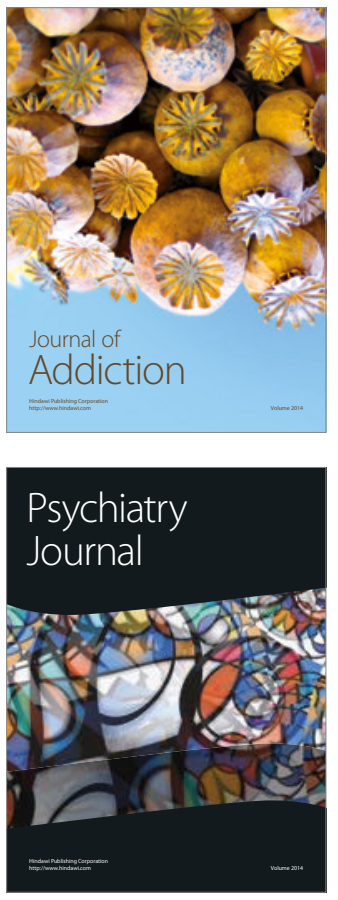

Child Development

Research

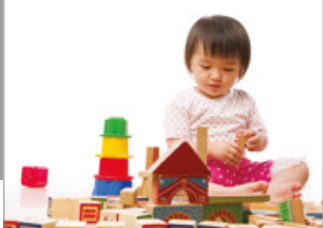

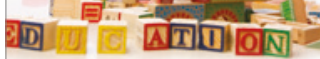
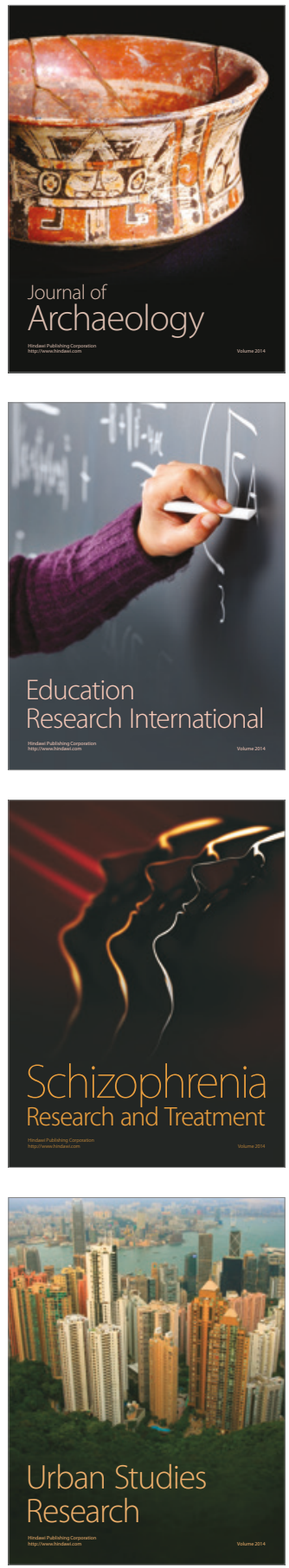